\title{
Outdoor Sculptures and Public History at the City of Thessaloniki (Greece): An Educational Action for Primary School Students
}

\author{
Orfanidis Dorotheos \\ University of Western Macedonia
}

\begin{abstract}
In the field of public historiography, we present the open-air public sculptures that were placed from the late 19th century until now in the city parks and the streets of Thessaloniki. The research question concerns public sculpture as a channel of aesthetic, urban and historical "mythology", but also as a historical and public discourse aiming at its educational utilization. The collection of material is in the field of on-site historical research and digitization of the material. The dynamic introduction of new technologies and digital media, their widespread use and the opportunities they provide are the starting points for new discussions and searches for their better use in the field of public sculpture teaching. We recommend teaching digital tools (webpage, smart phone \& tablet application) so that educators, teachers and animators can "present" with public sculptures.
\end{abstract}

\section{Introduction}

This study is a teaching proposal supporting public outdoor sculpture as a research and teaching material in primary education. In the lesson of history, children are both recipients, but they can also become small researchers, producers and transmitters of new historical material. The findings of a study by the Pedagogical Institute [3] that students do not have historical knowledge and do not love History highlights the difficulty of the particular lesson and the need for visualizing the historical narrative, But also to highlight the history of children, their participation in historical events. Cultural History [4] began to develop with the end of World War II, with a shift towards the formation of "culture" and "culture" from the bottom: thus the cultural shift took place interdisciplinary with anthropology, sociology, Economics, psychology, cultural geography and political science. In cultural history, greater emphasis is placed on attitudes, perceptions, social order, nation, feelings, memory, body, gender, art, but also on representations (literary, visual or intellectual, Others) in the ways in which these categories are constructed. For this reason, the new cultural historians influenced by the theory of social construction do not employ these social categories as stable and unchanging, but as fluid. As documented [1], school history in the last decades of the 20th century shows a new scientific character, separated from the traditional and ideological models of the past. The student pupils interact with the past through heterogeneous, complementary cognitive sources, thus enhancing the understanding of the procedural course of historical knowledge. Historical visual literacy as an epistemological demand for the teaching of history is defined by concepts, a prominent place among which the ability to develop historical reflections maintains. The research and didactic interest concerns the development of the abilities of a) the association of historical events of the past with the present, b) the interpretation of historical events through opposing historical sources, c) the formulation of historical questions to the students, competencies that are basic components of the historical reasoning.

The research material has to do with 225 public sculptures that were located in the city of Thessaloniki from 1897 to the present day. With the help of public sculptures, we can teach awareness to the students, not only for the material carrier but also for the historical representations.

The research and teaching problem we are called upon to address is good innovative practices to raise awareness and empower the "recognition and recruitment" skills of visual historical literacy.

Thus the research questions also shape the contents of the teaching proposal:

- Which slogans and which open-air sculptures of Thessaloniki are located?

- What disasters or other civil / pupil interventions are detected?

- What do pupils and citizens recognize and learn from outdoor public sculpture on the streets and squares?

- What are the representations of public, historical, national and other outdoor sculpture in school textbooks and curriculum of the lessons of Art and History in Primary Education?

- What educational actions do we propose to combat the phenomenon and raise awareness among pupils, citizens about the "pollution" of projects?

The aim of the work is in a continuously evolving technological environment, students with the help of outdoor sculptures to come in contact with issues of 
public, local history in a multidisciplinary way with the help of natural sciences and conservation science. Use visual arts as a means of personal understanding and expression, and the creation of innovative tools and applications to be mobilized through the proposed education treaty (city parks and streets).

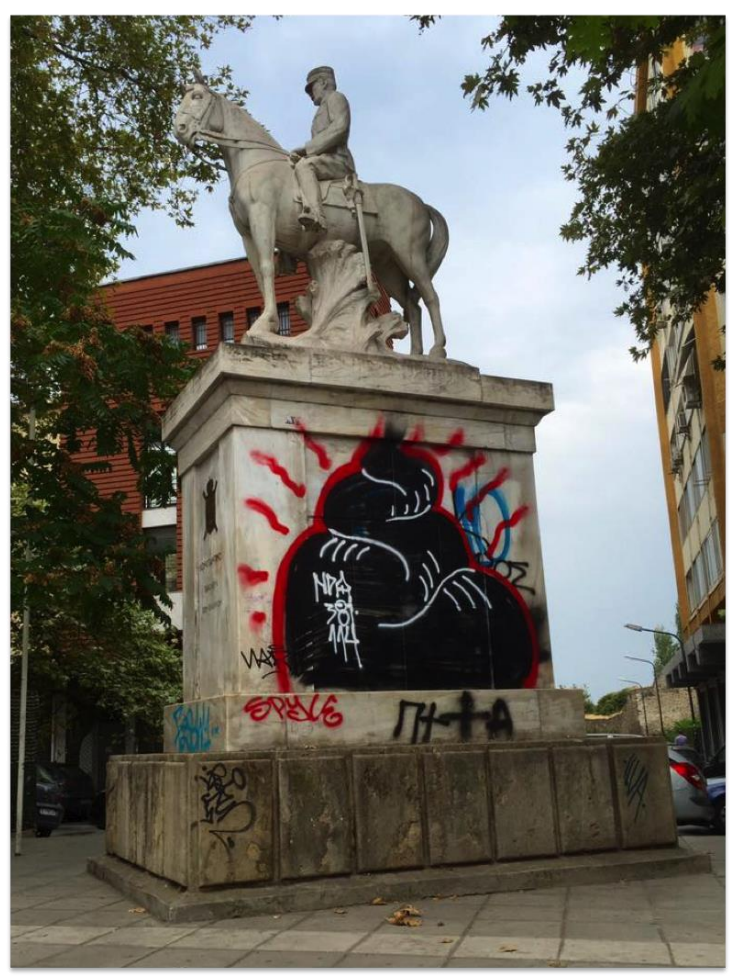

Figure 1. Graffiti in outdoor sculptures

(Thessaloniki)

\section{Innovative Educational Good Practices with the use of digital tools}

For the teaching of public sculpture we study the role of the school and the museum in the redesign of educational practices. In today's digital environment with the internet and social networks, the educational environment cannot continue on the path of anachronistic educational practices. Familiarity with new technologies and the use of the Internet provide the speed of information, where the "condition" of the classroom seems suffocating. We are at a crucial point in time, where previous generations, called 'digital immigrants', are trying to adapt to the internet and new technologies. For these man-types, knowledge, education and learning are differently understood. For digital natives, knowledge is flexible, open, collaborative, accessible on the Internet and presented with computer software (word, ppt). Students have the ability to do a lot of work at the same time, learning is fun and the whole world can be a learning environment. In contrast, "digital immigrants" regard learning as static and present it as a working text. It is the step-by-step process, considering learning a serious case with the promise of reward in the end. Thus, an ideal learning environment is school and class [15].

The research material in the study that we present is the outdoor sculptures and especially the monuments of the period (1896-2016) from the tradition of Thessaloniki to the present day. The research is part of the field of sociology of culture [2] and focuses on the question of managing the memory-sculpting word that appears more often, or even what is absent.

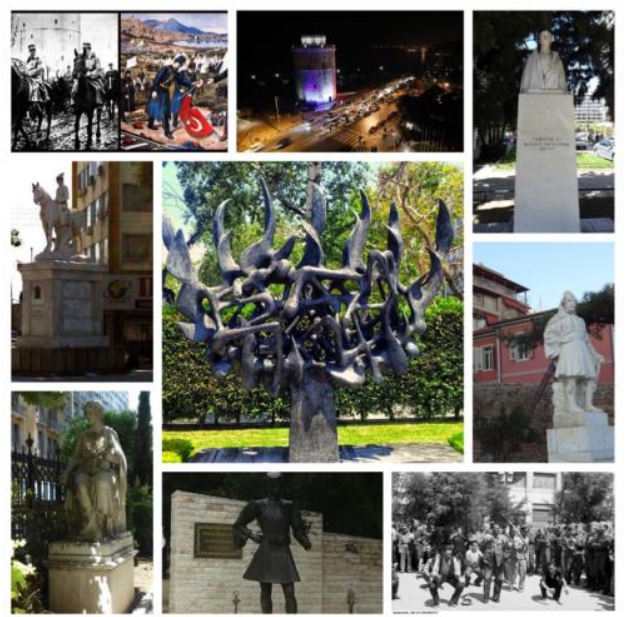

Figure 2. Public History and Public Sculptures of Thessaloniki

The questions that arise in the effort to recruit the artefacts can be oriented towards the subjective aspects of the signification and towards their practical aesthetic ideological use. The monumental, as well as the ideological landscape of each city is characterized by sharp contrasts. This material can be used in the field of cultural studies and social semiotics analysis of the image [8][9].

The cultural as an interdisciplinary direction with the aim of studying cultural practices, are involved in the relations of power of the hegemonic culture. Thus, most of the times we approach the samples as products of hegemonic, official national and material production.

Ideal for the teaching of history is pedagogically defined diversity and elasticity, in terms of school activities, e.g. How to work, small or larger groups, as well as individual tasks. Thus, students are familiar with the different types of sources and are able to express their views not only in writing but also orally. Student involvement with sources and assuming the role of history is easier when pupils begin to function as groups rather than individually. The presence in the class of different sexes, economic, social and cultural differences can be transformed into tools that children will use to elucidate those points that exist in the sources and are not clear [12]. 
The public sculpture of a city is one of the many themes of Local History. However, the interest of the contemporary historian has moved beyond the research and recording of historical reality and the teaching of historical material. The contribution of art and image is accepted in the teaching of history. However, the pictures and visuals of the textbooks contain, as the text itself, stereotypes and heterostereotypes in the field of national history [8].

The public sculpture in the cities presents historical, sociological and visual-aesthetic interest as it manifests at a specific time and geographical axis by the artists. The choice of space is decisive for the aesthetic result and the integration of the sculpture into the urban environment.

In a set of 225 sculptures located in Thessaloniki (1897-2016), the themes and styles, the sculpture materials, the artists' biographies, the selection of placements, the slogans that have been "painted" involve children and / Teachers with issues of historical and aesthetic involvement, but also critical "deconstruction" of the stereotyped academic public sculpture.

\subsection{Educational Action}

For the educational action, we need to study three important factors for better targeting and greater efficiency; the purpose of teaching the art and history lessons, developing modern methodological approaches, and defining this field study.

According to the design of the teaching proposal, I propose three meetings, where the first and the last will be held in the classroom, with the main educational activity taking place in the place where the open-air public sculpture, namely in situ.

The design and implementation of a school, museum or other program is only meaningful when a clear educational policy has been established. The choice between theories and methodologies is great, as it depends on the values and attitudes that we want to encourage each time. In this chapter, a brief overview of the theories on knowledge, learning and teaching with the greatest impact on modern Museopedagogy will be attempted. The following conclusions have been made possible by the interdisciplinary elaboration of the principles of Cognitive and Evolutionary Psychology and pedagogical practice.

According to the constructivist learning model (Constructivist learning), the learning process is not exhausted in the simple accumulation of knowledge that the person assimilates passively from his external environment. It presupposes, on the contrary, an energetic relationship with the physical and social environment, in which senses and thoughts work together, in order for the individual to critically interpret, interpret and understand and ultimately to handle autonomously the representations and stimuli from the inside and abroad of the world. The information is not simply added to one another but is constantly reclassified and reorganized into the person's experience. The validity of old and new knowledge is not judged by their degree of similarity to an objective, undeniable truth, but based on the compatibility of their relationship and functionality, so that they can be translated from theoretical forms into actions.

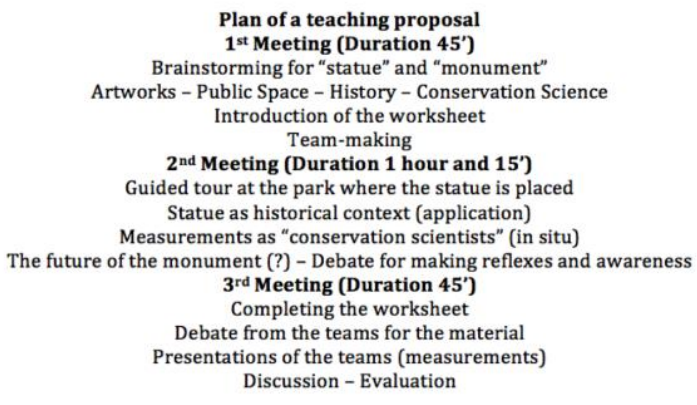

Figure 3. Plan of teaching Proposal

The concepts of "right" and "wrong" exist only to distinguish what emerges from tangible elements [14] than cannot be supported by evidence and put into practice. In a particular coincidence, the theory of structured learning itself is "built" by various fathers of modern progressive education. As early as 1916, John Dewey in his book Democracy and Education writes that learning stems from experience, provided that the action is connected with thought: "To think, in other words, is a deliberate attempt to discover special relationships between what we do and the consequences that follow, so that the two are a continuation" [12].

During a project, participants - students do not only learn about the content of their individual and group research. They express opinions and formulate oral or written ideas, realize their learning needs, take actions and engage in democratic exchange of views and collaborative implementation. Initiating and resolving problematic situations are by themselves a cultural value as they enhance the political self-confidence of individuals and groups [11]. The design and execution of each action perceives both the possibilities and prospects of individual contribution to a collective work, as well as the rules and stages of participation in a democratic system. Project participants are invited to make joint decisions on a variety of issues, such as setting up teams and assigning roles within them, setting up a timetable, (self) reviewing processes, and solving problems such as disagreements and confrontations between relationships, deviations from the original goal, difficulties in approaching other partners, etc. According to its definition, the project ends when the original purpose (completion 
of a research on a particular topic or improvement of a skill) is achieved, when it is presented, inside or outside the narrow boundaries of the team and workspace, the result of the research (with one exhibition, one event, etc.). By completing the contemporary demands in Pedagogy, we will take the lead from the need for a holistic view of the phenomena of our time that we touched upon in the Introduction to discuss the principle of the interdisciplinary approach.

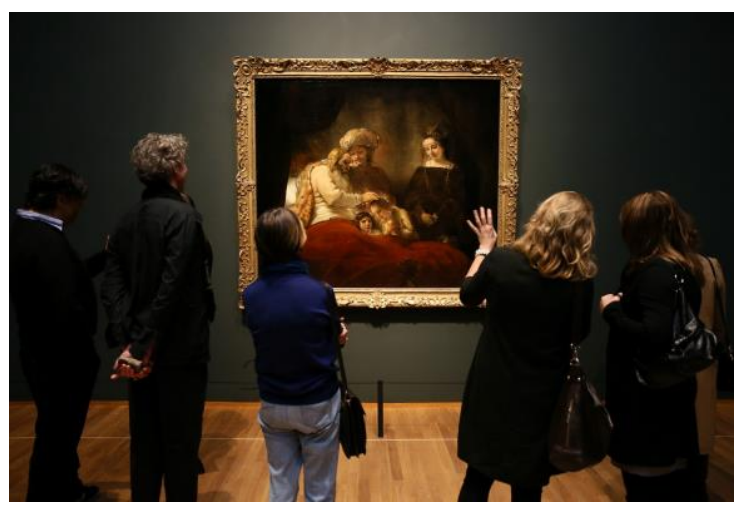

Figure 4. Educational program at Rijksmuseum (source: The Rijksmuseum)

Also, the characteristics of Educational Actions are:

1. They aim to bridge the gap between the citizen and the cultural heritage.

2. They refer to the "museum object" in the broader sense of the term, while utilizing other types of supervisory means.

3. They seek to uncover the meanings of objects, to transmit information to a variety of human communities, to discuss the culturally different, to connect with yesterday.

4. Are thematically organized presentations that focus on selected museum objects or aspects of a monument / space.

5. Objects are used in a variety of combinations, creating variations of narratives and paths in space.

6. They are addressed to a variety of audiences and adapted to the relatively homogeneous characteristics and needs of each group.

7. They are based on the model of active learning and the experiential approach.

8. Plan and evaluate based on a clear targeting.

9. They have a specified duration, structure and content.

10. They use media and techniques from the Pedagogic field, and use printed, 3D and digital educational material.

11. Designed by specialist professionals (museum educators?) They are determined by the ideological starting point and the theoretical tools of the designer, as well as by the wider policy of the designer.

In Greece, discussions about history and its meaning have grown. What is the role of this knowledge, what is its social utility? Its role is twofold: initially, to give a group, to a nation their memory, to restore it and then to help us understand the past, the links of the present to the past. In school history, the road to the history lesson of the "others" opens, and thus the story acquires a human face [5][6]. In addition, it is evident from the subject of school textbooks and pictures that it is being investigated through the sources. The new historical subjects are recognized through the shift of interest in gender and generation: children, the elderly, the formal and informal associations of women and men. Still, there are interpretations of the views of the subjects, while at the same time there is a "conciliation" of historiography with many scientific disciplines, such as sociology, anthropology, multidisciplinarity [10].

The "on site" museum actions are part of the debate about the democratic museum that attempts to transcend its limits in the literal and metaphorical sense of the term to meet new - often unknown categories of audience. Through traveling exhibitions, autonomous mobile cultural units, museums and community-based programs, the museum carries objects from its collections, and especially the ideas that surround them, in a variety of spaces. Its goal is to approach social groups that for different reasons - do not have the possibility to visit the museum building or feel that such a visit does not concern them. Schools, cultural centers, libraries, prisons are just some of the places where these cultural units, with the support of specialized museum staff and local authorities, implement the socio-educational role of the museum and help to establish a substantive and stable relationship with the community.

The typical course of a project (thanks to its 'liberal' nature, the method may be variants) could be as follows:

- Free expression of ideas and formulation of content and methodology for approaching a subject

- Evaluation of the above by all members of the team

- Democratic decision making on general and individual handling

- Programming actions and assigning tasks to individuals and subgroups

- Execution of decisions

- Regular interruptions of feedback and feedback on each subgroup and between subgroups

- Communicating the results of the research and discussion

- Critical evaluation of the whole process

- Presentation of the project to others (optional) 
The research interest in the school manual and its use by the teacher and the pupils increases at the end of the 20th century in the field of changes taking place in Pedagogical Science, school pedagogy, didactic research, school sociology, comparative pedagogy, educational reform. Our concern concerns the reading and exploitation of this historical material by teachers and pupils because the instructions given in the teacher's book and the training of teachers as it results from the studies in the Pedagogical Departments do not meet the requirements of the school manual on the use of sources in the history lesson [3] and in the lessons of the Visual Arts.

\subsection{Innovative educational tools}

The "portable conservation science toolkit" for the instructor-animator offers possibilities to use high-tech portable tools (temperature-humidity-wind meter, usb microscope, camera-shooting drone, etc.). Significant is the contribution of material science, experimental small-scale insitu, (metric measurements), and the original illustrated story (comic) to mobilize students.

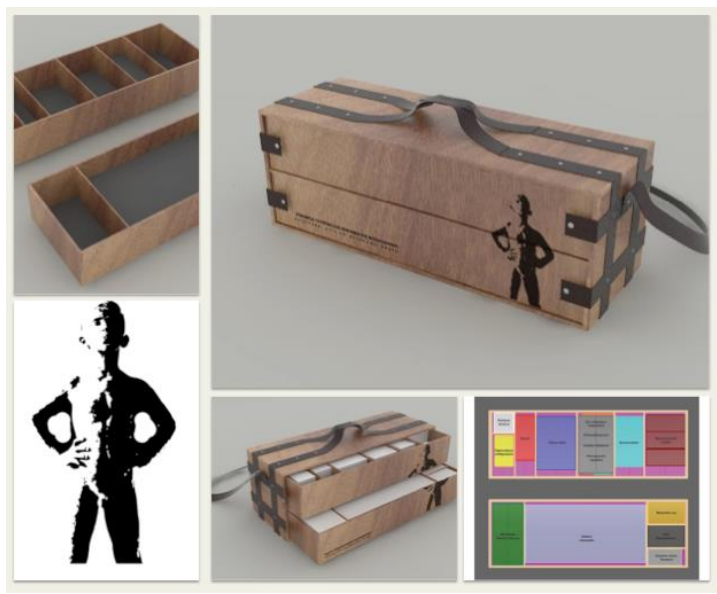

Figure 5. Photorealistic image of the portable toolkit

This enhances cross-media interaction for educators and students who will recognize the corrosion factors of outdoor sculptures and monuments such as:

1. Bio-erosion

2. Mechanical wear (breakage)

3. Climate pollution in the city due to air pollution

4. Corrosion of metal sculptures

5. Corrosion of glass sculptures

6. Corrosion of marble sculptures

7. Signing slogans.

The creation and use of the toolkit seek to build an experiential tool that can be used simultaneously in many school units and institutions. With original design, innovative means and a subversive approach to the issue of "pollution" of outdoor artifacts, we seek recognition, description and possible solution to the problem. Made of organic materials and small in size, it is characterized by mobility, elegance and light weight. The beneficiaries of the research / teaching proposal are:

1. Primary school pupils

2. Residents of Thessaloniki

3. Visitors to Thessaloniki

4. Visually impaired people (total \& partial) who have not yet had easy access to material for public history and sculpture

5. Parents, through the research proposal and the questionnaires will have feedback on the information they bring to their children

6. Teachers who will participate in self-correction and improvement of the educational process and acquire new tools.

The maintenance toolkit is a portable educational solution for the implementation of the training program consisting of state-of-the-art digital instruments and preventive maintenance tools. Media as a channel is the following:

1. Usb Microscope

2. Anemometer, Air Speed, Temperature \& Humidity Meter

3. 3D Virtual Reality Glasses

4. Lux meter

5. Drone

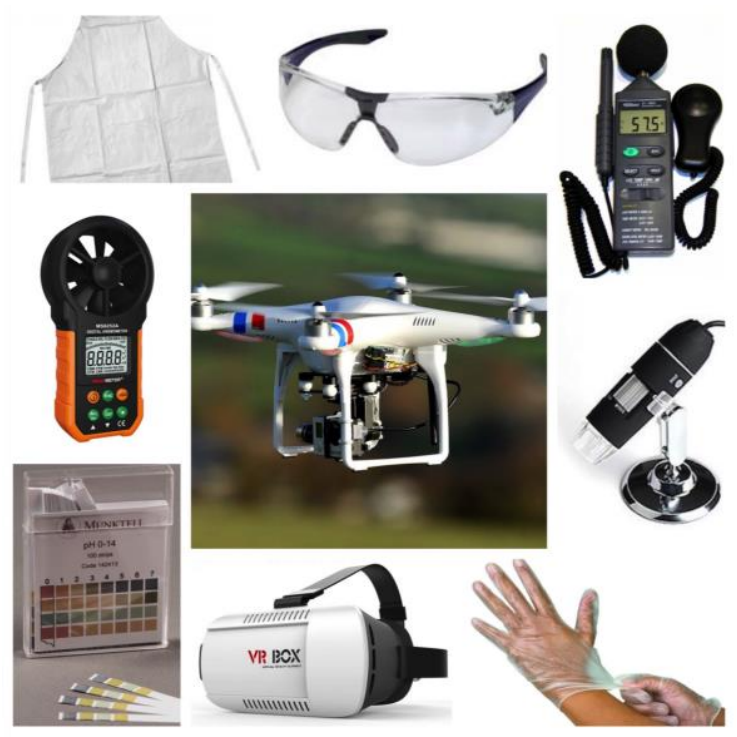

Figure 6. Conservation Science tools

Illustrated story seeks activation - mobilizing pupils on issues of outdoor sculpture. They will dictate methodologically recording and photographing either the design of outdoor sculptures in the worksheet with the illustrated story. In the end, there is a last framework of work that is empty, so that they can themselves as "responsible 
citizens" make it possible for the end of the story. Using visual arts (design), students will look for the symbols of personal intelligence for interactive engagement.
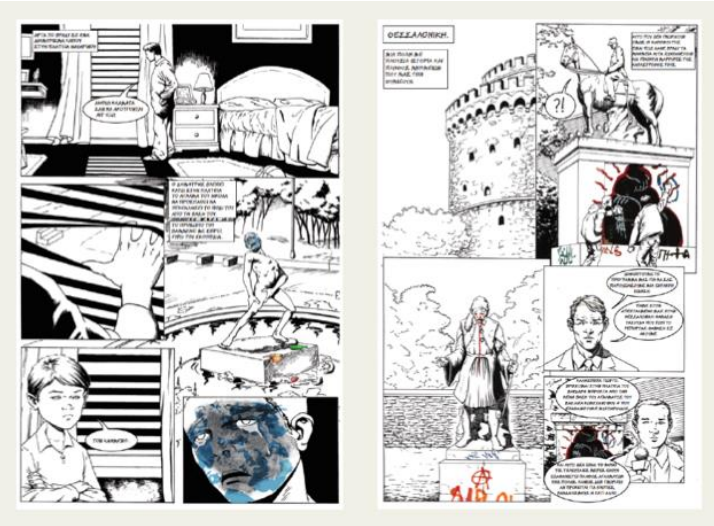

Figure 7. Illustrated story

Indicatively from all the sculptures we choose that of Nikolaos Pavlopoulos (1968) "Whispering child", because it is depressingly meaning "innocence, naivety and childish nakedness"

The parameters that are associated with the design of an Interpretive and Educational Activity in Cultural Reference Areas:

1. Select an application space

2. Select audience - application group

3. Select a theme

4. Defining objectives

5. Ability to connect with school matter

6. Selection of authentic material items: exhibits / aspects of the monument / sites of archaeological site, etc.

7. Define duration

8. Define Structure

9. Define routes

10. Production of supplementary surveillance material

11. Selection of pedagogical tools / techniques

12. Production of printed support material

13. Use of museum gears - lending material

14. Bibliography study

15. Set up practical issues

16. Evaluation

17. Connection to follow-up activities: school classroom, other cultural reference areas, etc.

\subsection{Application Goals}

Educational applications are an area characterized by innovation and originality and enabling the educational process to be supported outside the school environment. Thus, students can:

- learn digitally and experientially, the values of sculpture, visual arts, preservation, protection and restoration of monuments, public history, physical and environmental education

- Citizens and workers in educational and cultural, tourist structures to take on the values of outdoor public sculptures and monuments in urban parks and city streets in the field of targeted visual literacy.

\section{Strolling around Thessaloniki}

History, sculptures, monuments

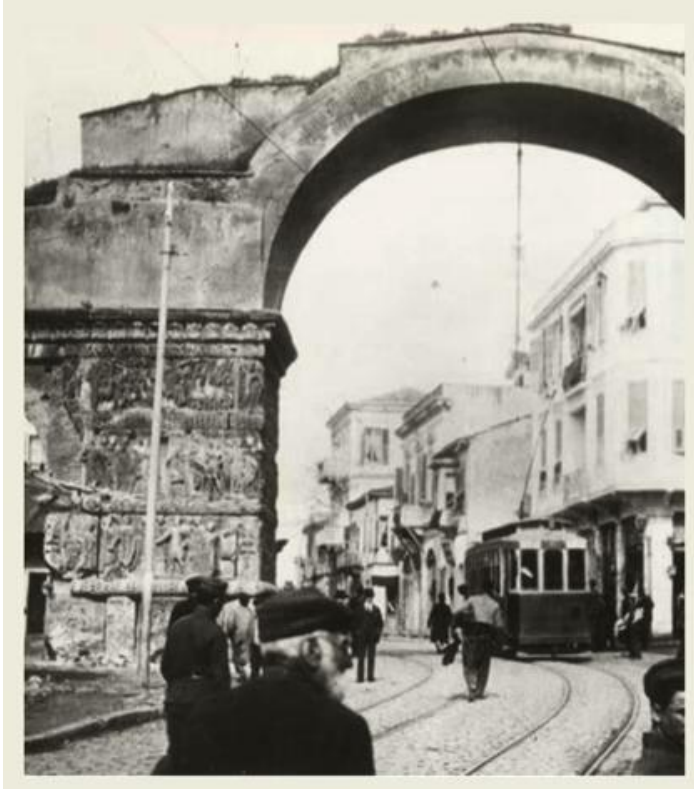

Figure 8. Application for Public Sculptures \& Public History
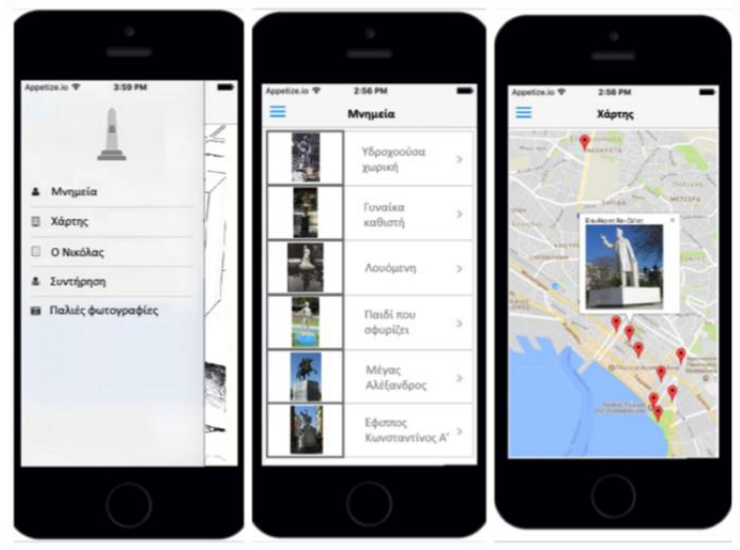

Figure 9. Index of the Application

In particular, the benefits of the research proposal for Primary Education are: 
- Be taught experientially, the values of conservation science and natural sciences

- to acquaint students with the values of public sculptures and monuments in urban parks and city streets

- get to know the public \& local history

- be aware of issues of public sculpture pollution.

The purpose of the application is to present various monuments in Thessaloniki as well as to raise awareness and information on issues related to their preservation.

The application menu consists of the following options:

- Monuments

- Map

- Nicolas

- Maintenance

- Old photos

Monuments

The user of the application can see a list with the monuments. Choosing a monument will show its photo as well as the related information. More specifically, they show:

- The name of the monument

- Thematic category

- The name of the sculptor

- Date of installation

- Detailed description of the monument

The user has the ability to view the application's monuments on a map. Selecting a point displays the name and photo of the monument in miniature. Clicking on the photo shows the details of the monument as described in the previous chapter.

\section{Contribution to the theoretical and applied scientific knowledge}

The contribution lies in both theoretical and applied knowledge. The use of existing practices and the creation of new criteria for research and evaluation of training programs will help in the future evaluation and critical evaluation of relevant programs. In addition, the creation of new digital tools will contribute to applied scientific knowledge as it will provide new tools for both museum and educational professionals to exploit new digital capabilities in the teaching process and respond to modern conditions and requirements.

In the field of cultural studies, the demand for specialized high quality and aesthetic tourism products has been observed in recent years. To meet these needs, a broad network of collaborators, modern infrastructure and harmonization with innovative international practices (internet use, innovative tourism products) through a design based on alternative and special forms of tourism are required. Some of the main types of tourism as historical, educational, cultural, urban tourism, conference, sustainable, alternative, environmental will be supported by the deliverable of the proposal in both theoretical and empirical.

\section{Discussion}

Research material has been recorded, digitized and analyzed in socio-textual and interpretive techniques by documenting the works. The teaching proposal is in the planning phase and will be implemented in the next school year in Primary Education schools in Western Thessaloniki.

\section{References}

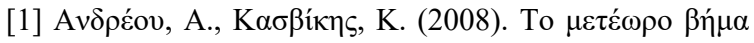

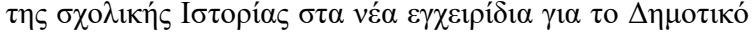

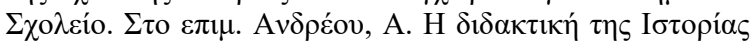

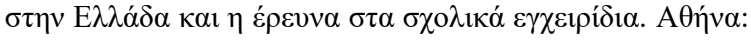

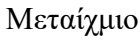

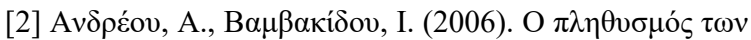

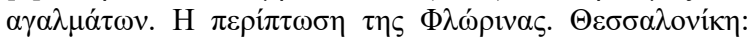

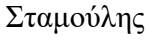

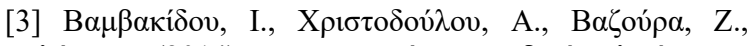

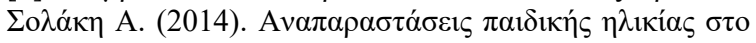

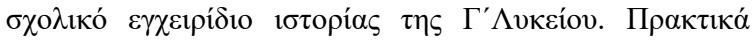

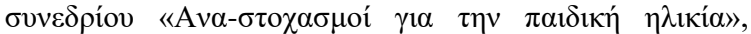
ТЕПАЕ АП囚 31/10/2014-1/11/2014

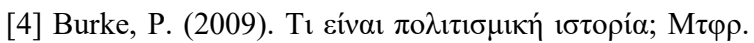

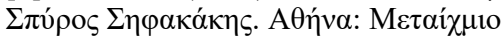

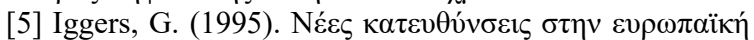

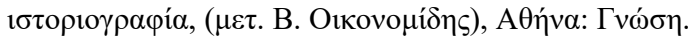

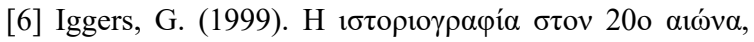

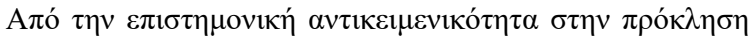

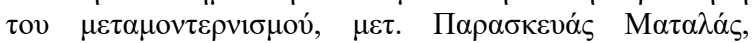

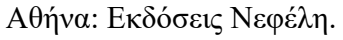

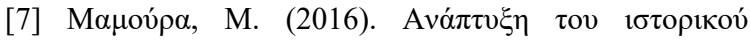

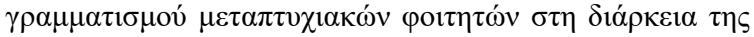

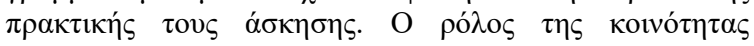

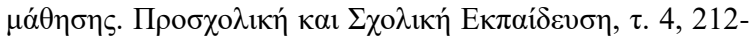
225

https://ejournals.epublishing.ekt.gr/index.php/education/art icle/viewFile/1936/10175.pdf

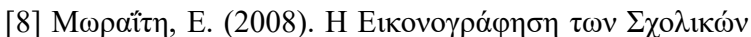

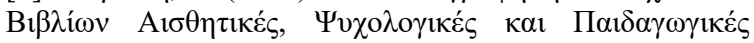

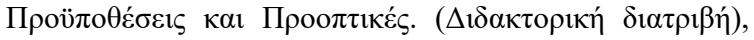

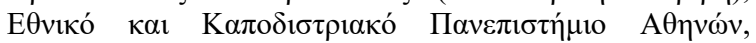

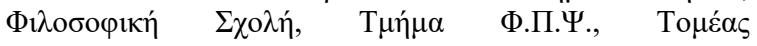

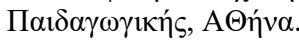

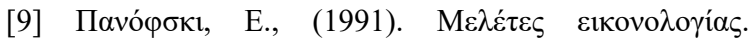

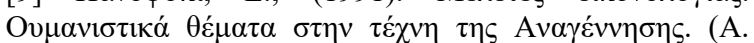

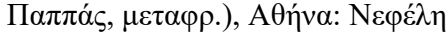

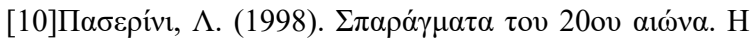

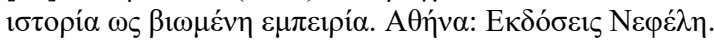

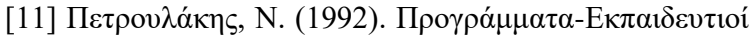

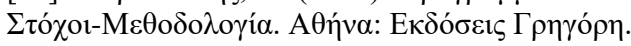




\section{Foreign language}

[12] Cuffaro, H., Shapiro, E., Kamii, C., Koutsouvanoy, E. Theory and Methodology at Preschool Education. Thessaloniki: Patakis Publication

[13] Hein, G. (1998). Learning in the Museum, London and N. York: Routledge.

[14] Palfrey, J., Gasser, U. (2008). Born Digital. Understanding the first generation of digital natives. New York: Basic Books.

[15] Portal, C. (1987). The History Curriculum for Teachers. Philadelphia: The Falmer Press 